\title{
A comparison of the carbon footprint of pavement infrastructure and associated materials in Indiana and Oklahoma
}

\author{
Rachel D. Mosier', Sanjeev Adhikari ${ }^{2}$, Saurav K. Mohanty ${ }^{3}$ \\ ${ }^{1,3}$ Construction Engineering Technology, Oklahoma State University, USA \\ ${ }^{2}$ Department of Construction Management, Kennesaw State University, USA
}

\section{Article Info}

Article history:

Received Nov 21, 2019

Revised Feb 11, 2020

Accepted May 14, 2020

\section{Keywords:}

Carbon footprint

Carbon sequestration

Construction carbon

Greenhouse gas

Sustainable pavement

ABSTRACT

Although often overlooked, infrastructure has a significant role in modern society. It is necessary means of transportation for goods and services needed to support commerce. It is this need and the need for continued economic development that causes the continuous infrastructure construction and its' associated greenhouse gas emissions. Infrastructure construction requires energy to process raw materials, transport, mix and final construction. Greenhouse gas emissions from pavement sections have previously been identified for pavement preservation techniques. This research further evaluates greenhouse gas emissions for typical pavement sections from Indiana and Oklahoma to determine the carbon footprint based on linear foot of pavement. The comparison of $\mathrm{CO} 2 \mathrm{e}$ of two typical roadway sections finds the difference in carbon footprint since variation in their minimum roadway. The carbon footprint of typical utility pipe with HDPE produces minimum $\mathrm{CO} 2 \mathrm{e}$ and steel produces maximum $\mathrm{CO} 2 \mathrm{e}$. Soil base remediation options produce minimum $\mathrm{CO} 2 \mathrm{e}$ and stabilized aggregate base produces maximum CO2e. Carbon offsets are determined by choosing vegetative options, soil remediation methods and appropriate pavement. This study is limited to a few pavement sections with a small variety of typical anticipated carbon offsets that would be seen in roadway construction. The index presented allows users to simply quantify benefits of the carbon offsets.
\end{abstract}

This is an open access article under the CC BY-SA license.

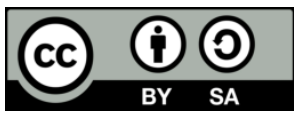

Corresponding Author:

Rachel D. Mosier,

Construction Engineering Technology,

Oklahoma State University,

570 Engineering North, Stillwater, OK 74078, USA.

Email: rachel.mosier@okstate.edu

\section{INTRODUCTION}

The challenge of global climate change has inspired change in Greenhouse Gas (GHG) reduction strategies for the construction, maintenance and rehabilitation of transportation infrastructure [1]. The carbon footprint of infrastructure pavement projects is determined based on calculations performed using Carbon Dioxide equivalents (CO2e) of GreenHouse Gas (GHG) emissions in construction quantities. The primary GHG emissions include life cycle emissions in the raw material acquisition and manufacturing phase, transportation or hauling phase and the pavement construction phase. The secondary emissions include emissions due to vehicular use and maintenance operations during the service life of the pavements which are not included in this study. 
The typical GHG emissions associated with the construction and maintenance of infrastructure pavement are carbon dioxide $(\mathrm{CO} 2)$, nitrous oxide $(\mathrm{N} 2 \mathrm{O})$ and methane $(\mathrm{CH} 4)$ [2]. To compare construction project materials and components, the carbon footprint, a measure of GHG emissions expressed as equivalents of carbon dioxide emissions is determined. The case studies presented benchmark and estimate footprints to effectively reduce emissions in future projects. The carbon footprint identified is also evaluated using existing sustainability rating systems. Environmental emissions have begun impact pavement management decisions, partially in response to benchmark tools which identify GHG as a metric [1, 3]. Since the 1980s, transportation infrastructure management has been a topic of importance due to growing government expenditures and user costs [4]. However, little research has monetized environmental emissions [5]. The United States Department of Transportation (USDOT) Federal HighWay Administration (FHWA) has provides some direction through technical reports on Life Cycle Assessment of Pavement [6]. The FHWA has made a variety of tools available through their website like Benefit-Cost Analysis (BCA) and Life Cycle Cost Analysis (LCCA) software [7].

Previous studies include predominantly international applications including; an examination of the carbon footprint of asphalt and concrete pavements in Ontario, Canada. Brown [8] reviewed the carbon footprint of a 50-year life cycle of asphalt pavement built as a Perpetual Pavement. Previously the carbon footprint of roads in the United Kingdom has been measured using Calculator for Harmonised Assessment and Normalisation of Greenhouse-gas Emissions for Roads (CHANGER), an international assessment tool [9]. Other international research has been published on this topic [10-12]. Melanta et al [13] proposed the Carbon Footprint Estimation Tool (CFET) for the estimation of greenhouse gas (GHG) emissions and other air pollutants from construction projects that are associated with roadways and other components of the transportation infrastructure. Other case studies have been performed for the carbon footprint of infrastructure in China and South Africa, which focus on drinking water [14-16].

Mosier et al. [17] previously provided a cost index for various pavement preservation options, proposing criterion that integrates sustainability with initial cost to justify investing in higher cost treatments on a basis of enhanced sustainability using the carbon footprint as a metric. A cost index provides a simple way to enhance pavement sustainability by providing a "shopping list" of sustainable options for the decision-making process, using initial cost, life cycle cost, and carbon footprint. The case studies herein provide an extension to the carbon footprint cost index of the previous study. This research has focused on associating many pavement infrastructure materials with their carbon footprint based on the linear foot of pavement in the United States. Other research in this area has performed similar studies in Canada, China, Spain and the United Kingdom [9-12]. This allows a comparison of current bid price per linear foot of pavement to carbon footprint in linear feet.

Pavement carbon footprint analysis has been performed in the past without making any determinations for subsurface treatment or the larger project [18]. The carbon dioxide equivalency for bridge design has previously been developed [19] and was applied to determine the embodied CO2e and estimate the performance of a bridge deck from a sustainability perspective. A ranking scale was identified by establishing a mathematical relationship between a bridges' $\mathrm{CO} 2 \mathrm{e}$ and its structure for parametric estimating of its embodied CO2e to gauge a bridge's sustainability [19].

An additional note, carbon offsetting is a controversial task. There is very specific research on the carbon footprint of construction materials using trees plantation on carbon offsetting [20, 21]. However, when trying to get a clear understanding of trees to plant to offset greenhouse gasses as $\mathrm{CO} 2 \mathrm{e}$, the maintenance and longevity of the trees themselves must be a factor [22]. This research highlights on used of trees or alternative materials to reduce the carbon footprint rather than a purchased carbon offset or carbon tax.

As illustrated through existing literature, there is still much to be known about the carbon footprint of infrastructure projects, more specifically pavement projects. Further to help best understand the actual carbon footprint, it would essential owners and engineers to consider all carbon offsets on the project. The index method assists owners and engineers for comparisons between two project elements. Carbon footprint values are utilized by infrastructure sustainability rating systems as discussed follows.

\section{Sustainability rating systems}

Green construction responds to rising concerns about pollution, population explosion and environmental degradation. The need for a strong economic, social and environmental benefit of green infrastructure has come to the forefront through sustainability benchmarks and attempts have been made to incorporate green elements into both project design and construction. Sustainability metrics such as Infrastructure Voluntary Evaluation Sustainability Tool (INVEST), Greenroads [23] and the United States Green Building Council (USGBC) Leadership in Energy and Environmental Design for Neighborhood Development (LEED-ND) are commonly used in highway construction. INVEST focuses on sustainable 
practices through state and regional level programs and may not apply to a single municipal project [24]. Greenroads has a group of credits focused on pavement materials and design. LEED-ND for neighborhood development which applies to pavement [25] through the recycled and reused infrastructure credit. The Envision rating system produced by the Institute for Sustainable Infrastructure (ISI) is a useful sustainability metric to apply infrastructure projects. This research uses the Envision rating system as it supports more infrastructure sustainability, specifically carbon footprint and greenhouse gas reduction [26].

The Envision rating system houses 60 sustainability criteria called "Credits" organized into 5 main categories: quality of life, leadership, resource allocation, natural world and climate and risk. As indicated above, there are a variety of choices for rating systems. Envision was chosen for evaluation due to its focus on the carbon footprint for infrastructure. This research attempts to utilize some of the credits listed in Envision to quantify the methodology to reach a better standing in creating a more sustainable approach in choosing construction materials and procedures affecting the carbon footprint of a pavement section, starting from design to operation. This research considers 5 different Envision credits namely RA1.1-Reducing Net Embodied Energy, CR1.1-Reducing Greenhouse Gas Emission, RA1.2-Supporting Sustainable Procurement Practices, RA1.3-Using Recycled Material and RA1.4-Using Regional Materials [26]. This paper uses CO2e as a proxy of embodied energy and greenhouse gases for simplicity in the calculations. For credits; RA1.1Reducing Net Embodied Energy and CR1.1-Reducing Greenhouse Gas Emissions, the net embodied energy of the infrastructure can be reduced into 2 ways, reducing the quantity of material or selecting material with lower embodied energy [26].

The case studies review how substituting a different material with a lower embodied energy affects the calculations. Choices of different subgrade stabilization methods with lower footprint in addition to a carbon offsetting like trees or utility pipes which reduce the carbon footprint significantly along with the embodied energy are made and are directly related in the greenhouse gas emission calculation. The calculations for two different types of roadway section in Fishers and OKC have shown a distinct difference of 70-80 (kilogram) $\mathrm{kg}$ of $\mathrm{CO} 2 \mathrm{e}$ per linear feet of the roadway section which relates to $70-75 \%$ reduction in greenhouse gas emission which are shown in the methodology section. This reduction in greenhouse gas emission would earn a "Superior" badge for the project under the Envision rating system. By evaluating two case study locations also illustrates how the choices in the minimum section also affects the $\mathrm{CO} 2 \mathrm{e}$.

The primary GHG calculation in this paper considers the raw material acquisition, manufacturing phase, transportation to the pavement construction phase [20]. Transportation is a significant consumer of fossil fuels and a source of greenhouse gas emissions. This paper completely utilizes the transportation distances identified in Table 1 which shows the distance requirements for each type of material procured. When at least $60 \%$ of the construction materials are procured within the specified distances as identified in RA1.4-Using Regional Materials [26] could earn an "Enhanced" badge under the Envision Rating System.

Table 1. Transportation distance estimates

\begin{tabular}{ll}
\hline \multicolumn{1}{c}{ Material } & Distance Requirement \\
\hline Soils and mulches & 50 miles $/ 80 \mathrm{~km}$ \\
Aggregates, Sands & 50 miles $/ 80 \mathrm{~km}$ \\
Concrete & 100 miles $/ 160 \mathrm{~km}$ \\
Plants & 250 miles $/ 400 \mathrm{~km}$ \\
Other materials & 500 miles $/ 800 \mathrm{~km}$ \\
(excluding equipment) & \\
\hline
\end{tabular}

Envision credit RA1.3-Using Recycled Materials encourages reduction in the use of virgin materials and avoid sending useful materials to landfills which otherwise could be reused or recycled and used as a building material for a green project [26]. Three different chemical additives; fly ash, CKD and lime, typically used for subgrade stabilization and provide a good basis for reducing the carbon embodied energy along with GHG emission significantly. The calculations for soil stabilization are included in the methodology section. Choosing any of the stabilization techniques prescribed in this research paper could earn an "Improved" badge under the Envision Rating System.

\section{Pavement sustainability}

Due to the chemical processes that occur in Portland cement production, for every $1,000 \mathrm{~kg}$ of Portland cement, approximately $730 \mathrm{~kg}$ of carbon dioxide is produced. Heating the aggregate and clay used to produce Portland cement to a temperature of around $1,450^{\circ} \mathrm{C}$ in the kiln causes the dissociation of the limestone and the production of about 60 percent of the carbon dioxide, which is released to 
the atmosphere. While comparing 50-year life-cycle greenhouse gas production, concrete pavement produced about $1610 \mathrm{CO} 2 \mathrm{e}$ tons $/ \mathrm{km}$ and asphalt pavement produced about $500 \mathrm{CO} 2 \mathrm{e}$ tons $/ \mathrm{km} \mathrm{[27,} \mathrm{28].}$

The bulk specific gravity of compacted asphalt ranges from 2.29 to 2.35 [29]. As specific gravity for Hot Mix Asphalt (HMA) is based on the unit weight or solid density of the compacted mix, the Rice value or $\mathrm{Gmm}$ is used as a basis for the specific gravity. The Asphalt Institute also provides guidance on specific gravities, pointing to 2.5 being a typical value [30]. For this research, we utilize an estimated specific gravity of compacted asphalt to be 2.32 which multiplied times the density of water in pounds per cubic foot (pcf) (62.4 pcf) provides a density of 144.77 pcf which is rounded here for simplicity to 145 pcf. Similarly, the density or unit weight of Portland Cement Concrete Pavement (PCCP) is well known. However, an average value has been identified for this work. The unit weight of concrete is commonly known to be between 140-150 pcf [31]. For this work the value of $145 \mathrm{pcf}$ will be used.

\section{Soil and subbase treatments}

Subgrade treatment consists of providing, placing and compacting one or more layers of soil along with chemical additives and water to achieve a stable subgrade, which are chosen based on the soil type, the ease of effort and efficiency. Chemical additives used to stabilize or modify the subgrade are either cementitious additives; fly ash or cement kiln dust, or lime additives. Aggregate base material may also be used instead of a chemical soil modification. Taking into consideration the engineering properties of soil are based on natural characteristics and the field or site conditions, therefore an average specific gravity value of 2.73 and density a of $170 \mathrm{pcf}$ is taken for all calculations of the carbon footprint in this paper.

The density of Portland cement is 1860 kilogram per cubic meter $(\mathrm{kg} / \mathrm{m} 3)$ [21] which converts to 115.87 pcf. The specific gravity of CKD typically ranges from 2.6-2.8 [32]. Using the average specific gravity of 2.7, the weight is approximately the same as soil or $170 \mathrm{pcf}$. Indiana Department of Transportation (InDOT) has provided soil modification specifications for CKD stabilization of sandy soils with suggested mix quantities of $4 \%-6 \%$ by weight [33]. An application rate of 5\% by weight will be used here. Hammond and Jones simplified the calculations by providing a CKD soil stabilized base carbon footprint of $0.06 \mathrm{~kg} / \mathrm{kg}$ which converts to $0.386 \mathrm{~kg} / \mathrm{sf} / \mathrm{in}$ of stabilization [21].

Fly ash is another frequently utilized additive for stabilizing soil for highway constructions. The specific gravity of flyash varies widely, from 2.0-2.6 [34]. The density of fly ash will be taken as 2300 $\mathrm{kg} / \mathrm{m} 3$ [21] which converts to $143.52 \mathrm{pcf}$ and will be rounded to $144 \mathrm{pcf}$ for simplicity in calculations. The American Coal Ash Association (ACAA) provides guidelines for stabilization of soil subbase using fly ash, where the replacement level ranges from $12-15 \%$ to the weight of dry soil [33]. The Oklahoma Department of Transportation (OkDOT) soil stabilization mix design states an optimum replacement level of $14 \%$ in stabilization of soil subbase in Oklahoma, which typically applies to all soil types except A7 (organic soil material) under the American Association of State Highway and Transportation Officials (AASHTO) soil classification method [35].

Subgrade stabilization using lime additive which is preferred for soil types which are categorized under the AASHTO M145 soil classification of A6 (silt-clay fine soil material) and A7 soil where the density taken into consideration for the carbon footprint calculation is $1200 \mathrm{~kg} / \mathrm{m} 3$ [21] which converts to $74.81 \mathrm{pcf}$ and will be rounded to $75 \mathrm{pcf}$ for simpler calculations. A range of application rates for lime has been established between 3\%-6\% by weight [36]. An application rate of 5\% by weight will be used here.

Localities may specify a variety of aggregates for base material. Aggregate base varies in density based on the material and compaction. For the localities included herein subbase improvements include No. 8 and No. 53 coarse aggregate base material blends as specified by InDOT [36]. An aggregate blend contains a variety of sieve size materials based on standard U.S. mesh or sieve opening sizes. A variety of densities have been identified for aggregate base materials from $100 \mathrm{pcf}$ to $180 \mathrm{pcf}$. Hammond and Jones [21] provide a density and carbon footprint in their Inventory of Carbon and Energy (ICE). The density provided by ICE is $2,240 \mathrm{~kg}$ per cubic meter which converts to $139.8 \mathrm{pcf}$ rounded to $140 \mathrm{pcf}$ for simplicity herein.

\section{Potential carbon offsets for infrastructure construction}

For a 24' roadway, the statutory right-of-way for most of Oklahoma is $66^{\prime}$ as identified in the Organic Act of 1890 as 4 rods wide with a rod being equal to 16.5 feet [37]. Although this is "shared" space by the property owner and the state, a clear zone [38] is required in the first 7'-10' either side of the roadway section. Along with highway signs, some low planting occurs in this area, including turf grass. Indigenous plants and xeriscaping would provide the best outcomes with the least amount of carbon emissions associated with installation and care. In OKC and Fishers xeriscaping is not indigenous and not considered here. However, there is plenty of research identifying the carbon sequestration value of native soils and xeriscaping. Bouchard et al. [39] provides some insight into the ditch area on a section with no curb. As the vegetation acts as a filter and swale, it also provides some carbon footprint reduction. 
Potential carbon offsets should be identified, especially those behind the curb or outside the roadbed. Many roadway projects include a variety of landscape elements. and trees may provide a carbon offset on average of 19 kilograms per year at maturity, which is between 12 and 18 inches in trunk diameter and typically over 30 feet in height $[40,41]$. Further other evidence provides carbon storage in trees and shrubs in grams per square meter based on land use. It is assumed that trees sequester carbon during growth. However, there is also some amount of loss due to lack of maintenance and death. Trees provide benefits in urban areas like shade and sequestering rainwater. Additional benefits include evapotranspiration cooling and wind speed reduction [42]. Turf grass and shrubs can also be used in carbon footprint calculations. Turf grasses are difficult to calculate for offsets due to fertilizer, irrigation and other maintenance like mowing [43]. In areas where other types of grasses or wildflowers are used, assumptions would change. Depending on the density and the life stage, Shrubs can provide $0.13-12.93 \mathrm{~g} / \mathrm{m} 2$ of carbon storage based on density of shrubbery [44].

The vegetative ditch offsets should be compared to an underground utility pipe. Many utilities are outside the traditional project scope of government entities and are self-performed by others. Some utilities may be provided by local government, like storm sewer, water lines and sanitary sewer lines. An in-depth analysis of these utilities is not provided here, but some discussion is merited. An Inventory of Carbon and Energy (ICE), has been developed by [21] specific to construction materials. A comparison of concrete, iron, steel, High Density PolyEthylene (HDPE), PolyVinyl Chloride (PVC) and vitrified clay pipe can be performed as well to make determinations as to the least carbon footprint. Like any other comparison, the pipe cannot be considered as a manufactured product alone, the transportation, setting and bedding activities must be analyzed.

Reductions can be contributed from other sources as well. Substituting fly ash or slag for PCCP can reduce associated GHG emissions [45]. Warm Mix Asphalt or Recycled Asphalt Paving can be used to reduce the carbon footprint as well. This is not an exhaustive list but meant to illustrate there are many alternatives to be considered. The study reviewed a variety of roadway types but is confined to a typical county road section with ditch. As such, there are no roadway lights or sidewalks. However, the framework can be extended and further applied to these additional items. Electrical items have continuing costs that are not considered here.

\section{RESEARCH METHOD}

A review of standard sections was performed for Fishers, IN (Fishers) and Oklahoma City (OKC), OK. Both municipalities publish typical sections online. This is unique to smaller government entities. A web search was performed for published standards throughout the United States. Departments of Transportation typically rely on design engineers for all of their highway sections. However, it is possible to find county standards, particularly for bridges. Published municipal roadway standards were found for cities in Florida, Indiana, Tennessee, Ohio, Oklahoma, and Washington. Locations in Fishers and OKC provided the most information online. An additional reason for focusing on these two locations is the location of the research team. As the research team already had knowledge of these locations, the locations became preferred for the case studies.

Starting from the roadway sections, an area per linear foot was determined. Roadways are typically bid per linear foot. Using the area per linear foot, an easy correlation can be made to cost. The area per linear foot also allows the different materials to be indexed for comparison. For HMA sections, tack coat is not included as the pay item for tack coat is frequently in gallons and not in linear foot. A standard for the carbon footprint or greenhouse gas emissions should be determined for roadways which can be compared to bidding for monetization. If GHG is calculated in bidding quantities like linear foot (LF) or square foot (SF) then the change in cost between options can be compared to the change in GHG. Greenhouse gases are frequently measured in terms of energy used in British Thermal Units (Btus), Joules or megajoules (MJ). The carbon footprint can be measure through the embodied energy (carbon) of a production cycle, frequently referred to as $\mathrm{CO} 2 \mathrm{e}$. Hammond and Jones propose using a common idea of cradle to gate, which indicates the production energy prior to leaving the factory [21]. Shipping would be accounted for separately. Chevotis and Galehouse use a similar approach specifying an expected travel circuit [20]. For this research, the calculations are presented in one set of units. Because the carbon offset due to trees is presented in $\mathrm{kg} / \mathrm{tree}$, the appropriate choice of units is the carbon emission of the materials in question or $\mathrm{kg}$ of carbon per unit.

Greenhouse Gas emissions were calculated for each of the pavement, stabilization and utility materials identified. The GHG for the different materials were converted to an appropriate biddable unit. In most cases the bidding unit is based on linear foot. The options are compared for the least carbon footprint. The two municipalities have similar roadway sections for width and drainage. This is not a comparison of 
the design of the two sections, but an illustration of choices that could be made. For OKC, a typical 24' HMA section with a ditch, the section consists of 3" Type B HMA over 6" Compacted Subgrade, and over 6" Stabilized Aggregate Base or 10" Stabilized Soil. The similar section for Fishers is noted as Main St./Secondary St. and consists of 1.5" Type A HMA Surface over 2. 5" Type A HMA Intermediate and 2. 5" Type A HMA Base, over 3" Type A HMA Base and 14" Stabilized Subgrade or 6" Compacted Aggregate Base No. 53 on 14" Stabilized Subgrade. The narrative description is tabulated in Table 2 with the associated carbon footprint.

\subsection{Carbon footprint}

Itemized list of carbon footprints has been determined by a variety of groups described in the introduction and those used for calculations here [20-21], which focus on typical items utilized in construction, although not exhaustive [46]. The carbon footprint of a linear foot of roadway construction has not been previously determined. The carbon footprint per linear foot of construction is necessary for engineers and owners for budget choices as compared with carbon footprint or greenhouse gas emissions. The carbon footprint of each of the individual layers of material is calculated based on volume of the overall section, a carbon footprint in $\mathrm{kg} / \mathrm{lf}$ can be determined. The GHG or carbon footprint is given in $\mathrm{kg} / \mathrm{ton}$. From densities identified in the Pavement Sustainability section, the $\mathrm{kg} / \mathrm{ton}$ of material can be found for either HMA or PCCP. Using standard conversions for weight per inch of thickness, the carbon footprint for inch of thickness is determined. This is a useful conversion as pavement thickness vary widely even in standard roadway sections.

Adding a stabilized base adds multiple variables to the equation. There are three basic options for chemically stabilizing soil base, by adding fly ash, lime, or CKD. Some methods use a mix of two chemicals, but that will be outside the focus of this research. For simplicity only one chemical additive is evaluated at a time, based on the application rates given above. Comparing both $\mathrm{OKC}$ and Fishers, there are four different depth of soil stabilization; 6", 8", 10" and 14". The carbon footprint for 1" of soil stabilization is based on the technique; with Fly-Ash providing $0.274 \mathrm{~kg} / \mathrm{SF} / \mathrm{in}, \mathrm{CKD}$ providing $0.603 \mathrm{~kg} / \mathrm{SF} / \mathrm{in}$ and Lime providing $0.812 \mathrm{~kg} / \mathrm{SF} / \mathrm{in}$. There are many options for reducing the carbon footprint of a roadway. Chevotis and Galehouse [20] have tabulated a variety of carbon footprints associated with roadway maintenance. Although the concrete, asphalt and base materials are considered additive in this paper, utilizing alternative methods like warm mix asphalt can be considered a potential reduction.

Trees are likely to be second only to soil for carbon sequestration in an urban environment [47]. Calculations for carbon sequestration frequently consider trees as a group making it difficult to apply a carbon offset for a singular tree. However, some research has focused on individual trees and more particularly street trees as a carbon offset [40-48] From research in the Twin Cities, values on a per tree basis were determined [39] and is provided in Table 2 adapted from that research. The adapted table uses a street tree lifespan of 50-60 years as provided by Strohbach at al. [22]. A standard tree spacing must also be identified.

Table 2. Carbon sequestration of trees (adapted from Akbari [41].

\begin{tabular}{lllc}
\hline \multicolumn{1}{c}{ Tree Type } & \multicolumn{1}{c}{ Carbon $(\mathrm{kg})$} & \multicolumn{1}{c}{ Tree Type } & Carbon $(\mathrm{kg})$ \\
\hline Norway maple & 160 & Robusta and Siouxland hybrid & 745 \\
Sugar maple & 145 & Kentucky coffee tree & 105 \\
Hackberry & 135 & Red maple & 140 \\
American and little-leaved linden & 265 & White pine & 210 \\
Black walnut & 150 & Blackhills (white) spruce & 165 \\
Green ash & 180 & Blue spruce & 335 \\
Species Average (Not including & & & 153.75 \\
Robusta and Siouxland hybrid) & 180 & Average Oklahoma and Indiana Species & 13 \\
\hline
\end{tabular}

As not all trees are available in all places and some trees exhibit unusually high sequestration rates, two averages for calculations were determined. An average was taken without the Robusta and Siouxland hybrid which exhibits exceptionally high sequestration rates. Oklahoma native trees include Black Walnut which is italicized in Table 3. Indiana native trees include Green Ash, Sugar Maple and Red Maple which are shown in bold. These native trees to our case studies were also averaged. Spacing may be determined by the designer or engineer for a roadway project. A crown of $50 \mathrm{~m}^{2}$ or $538 \mathrm{SF}$, or approximately 26 -foot diameter [41] is the basis for tree offsets. Using a slight overlap, trees will be assumed to be spaced 20' apart. This is a typical street tree spacing. Using the average carbon sequestration and a 50-year life cycle, a carbon 
offset per tree can be estimated somewhere between $150-180 \mathrm{~kg}$ over the life of the tree. Based on a 20' spacing the average carbon offset per linear foot would be $8.25 \mathrm{~kg} / \mathrm{lf}$.

Adding turf grass through the use of a vegetative drainage channel or ditch instead of a concrete channel or underground storm sewer is another carbon offset alternative. Like any other system, there is a carbon footprint to the installation of the system itself. Some additional choices may be made. When using a vegetative "filter strip" or ditch, a value of $36 \mathrm{~kg} / \mathrm{SF}$. may be used, calculated for a variety of locations in North Carolina. These values may be increased when using a wetland area or area which is continually wet [38]. Although these results may not be considered complete and for extrapolation to all locations, it is important to note that data could be compiled at other locations to obtain a locally appropriate carbon offset. Another option is to reduce the carbon footprint of the associated utilities. Based on the Hammond and Jones inventory [21], the carbon footprint for a variety of pipes can be determined. Using a 12" diameter pipe and weight per linear foot as a basis for consideration, the carbon footprint of typical utility pipe is provided in Figure 1.

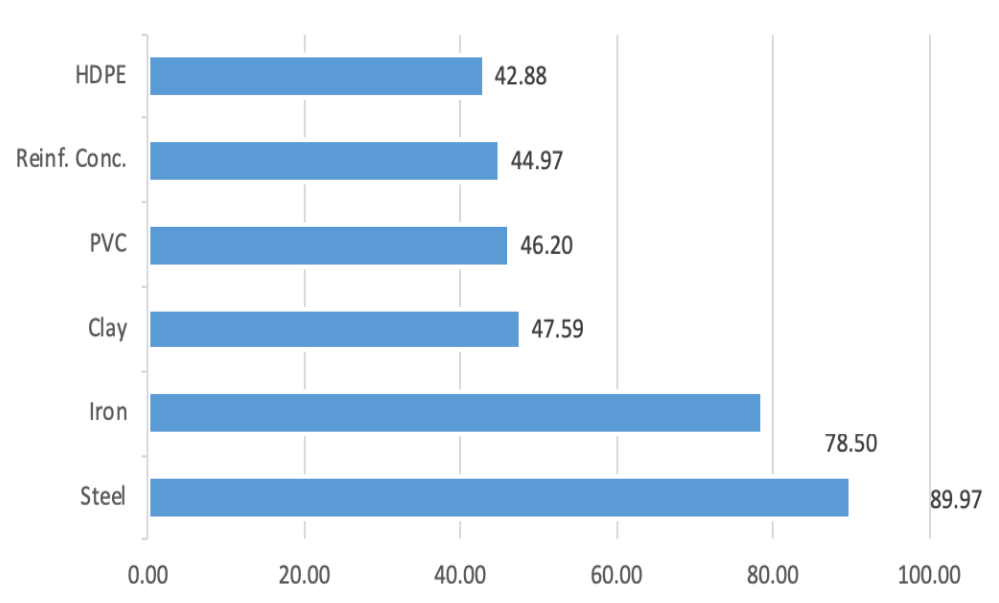

Figure 1. Carbon footprint of 12" diameter utility pipe per linear foot [49].

There are material choice limitations. In some areas CKD is required for sandy soils, in other locations, fly ash and lime is more appropriate. A similar requirement is true for water pipe versus storm water pipe, PVC may be required for water, while reinforced concrete pipe is acceptable for stormwater. By itemizing the carbon footprint to include all of the roadway section or the right-of-way limits, the total carbon impact can be determined. Since the right-of-way includes vegetation, the carbon offset will be examined.

\section{RESULTS AND ANALYSIS}

The purpose of this research was to determine a carbon footprint index. It is preferable to identify any greenhouse gas emissions and to identify opportunities for carbon sequestration. By providing both types of options, owners, designers and engineers can identify "shopping list" items for their roadway projects. The 24' HMA Roadway with No Curb will be examined in further detail. Soil stabilization options will be added and a utility pipe section. Trees will be considered in the roadway section to reduce the overall carbon footprint. Tabulating all of the options, a maximum and minimum carbon footprint are found as shown in Table 3.

The original pavement sections for both municipalities included options for base material. The soil stabilization methods are optional and may not be applicable in all locations. CKD is typically used in Indiana but may not be used in Oklahoma. However, CKD was the basis for calculation for the minimum carbon of both roadway sections AS shown in Figure 2. A subtotal was provided based on the roadway options only. To calculation the maximum including trees and utilities, only the maximum and minimum carbon footprint for pipe were considered, specifically steel and HDPE. Trees were subtracted to further reduce the minimum carbon footprint. The assumption is the worst-case for carbon footprint would be without street trees as an offset. 

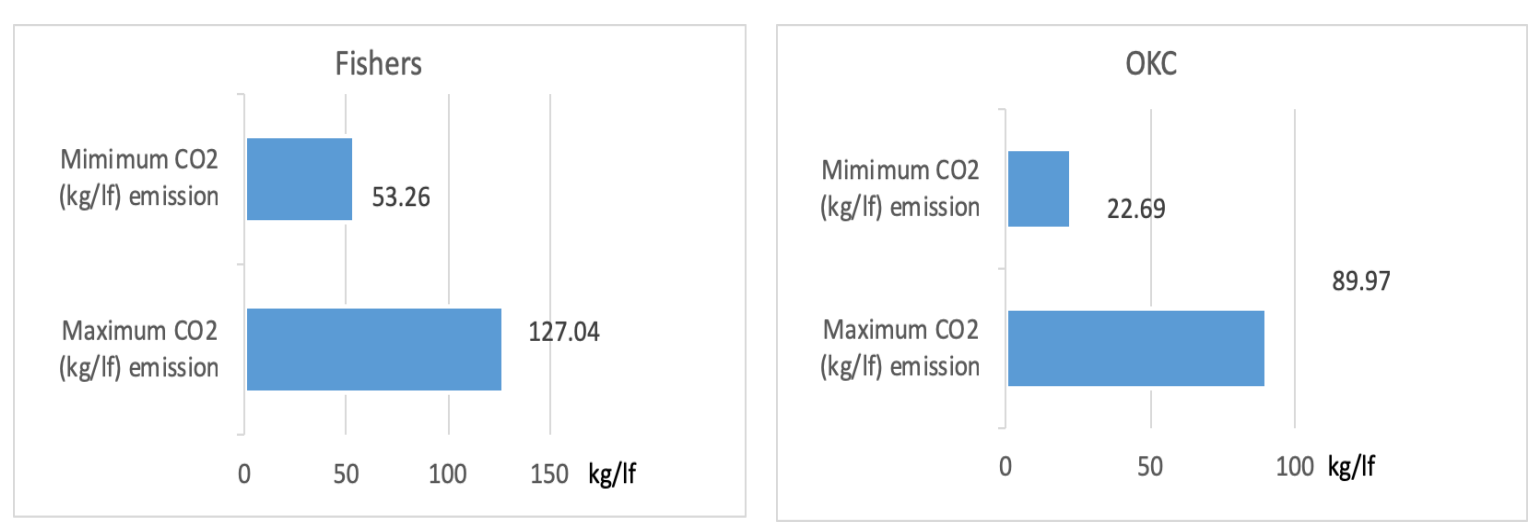

Figure 2. 24' comparison of $\mathrm{CO}_{2} \mathrm{e}$ in $\mathrm{kg} / \mathrm{lf}$ for two typical roadway sections.

Table 3. Total carbon footprint for a 24 ' hma roadway section

\begin{tabular}{|c|c|c|c|}
\hline $\mathrm{OKC}$ & $\mathrm{CO} 2(\mathrm{~kg} / \mathrm{lf})$ & Fishers & $\mathrm{CO} 2(\mathrm{~kg} / \mathrm{lf})$ \\
\hline 'Тур HMA Section 102 - 24' & & Main St/Secondary St & \\
\hline 3" Type "B" Asphalt & 21.67 & 1.5" Type A HMA Surface & 10.83 \\
\hline \multirow[t]{2}{*}{ 6" Compacted Subgrade } & 1.48 & 2. 5" Type A HMA Intermediate & 15.43 \\
\hline & & 2. 5" Type A HMA Base & 15.43 \\
\hline *10" Stabilized Soil & & 14" Stabilized Subgrade & \\
\hline Fly-Ash (14\%) & 2.74 & Fly-Ash (14\%) & 3.33 \\
\hline CKD $(5 \%)$ & 6.03 & $\mathrm{CKD}(5 \%)$ & 7.88 \\
\hline \multirow[t]{2}{*}{ Lime $(5 \%)$} & 8.12 & Lime $(5 \%)$ & 10.80 \\
\hline & & *3" Type A HMA Base & 18.52 \\
\hline Or & & Or & \\
\hline **6" Stabilized Aggregate Base & 11.43 & **6" Compacted Aggregate Base & 11.43 \\
\hline No Curb & 0 & No Curb & 0 \\
\hline Subtotal (Max.) & 34.58 & Subtotal (Max.) & 71.65 \\
\hline Subtotal (Min.) & 25.89 & Subtotal (Min.) & 56.46 \\
\hline Street Trees@20' o.c. & -11.5 & Street Trees@20' o.c. & -11.5 \\
\hline Pipe (HDPE Min.) & 8.3 & Pipe (HDPE Min.) & 8.3 \\
\hline Pipe (Steel Max.) & 55.39 & Pipe (Steel Max.) & 55.39 \\
\hline Total (Max.) & 89.97 & Total (Max.) & 127.04 \\
\hline Total (Min.) & 22.69 & Total (Min.) & 53.26 \\
\hline
\end{tabular}

Figure 3 illustrates the comparison of $\mathrm{CO} 2 \mathrm{e}$ of two typical roadway sections of OKC and Fishers. Table 2 has shown four options of base materials. These base materials are 10" stabilized soil with flyash, 10 " stabilized soil with CKD, 10" stabilized soil with lime and 6" stabilized aggregate base. Figure 3, Figure 4, Figure 5 and Figure 6 compare the $\mathrm{CO}_{2} \mathrm{e}$ of these base materials. While comparing these four base materials, 10" stabilized soil with fly ash produces minimum $\mathrm{CO}_{2} \mathrm{e}$ and 6" stabilized aggregate base produces maximum $\mathrm{CO}_{2} \mathrm{e}$.

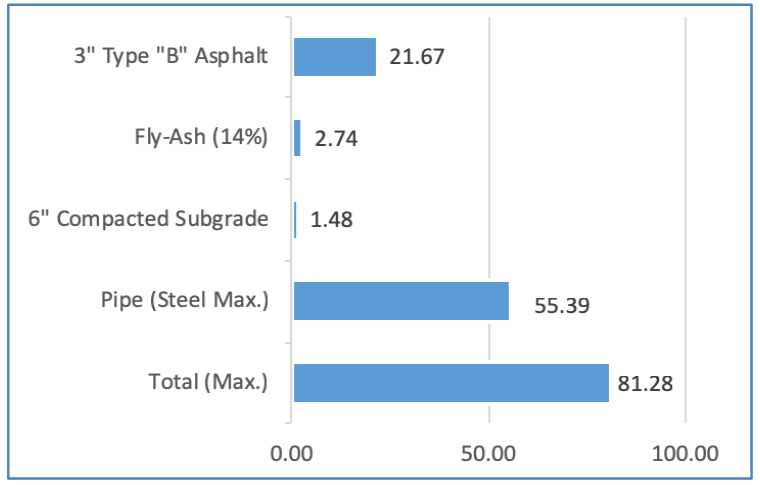

Figure 3. CO2e (kg/lf) using flyash

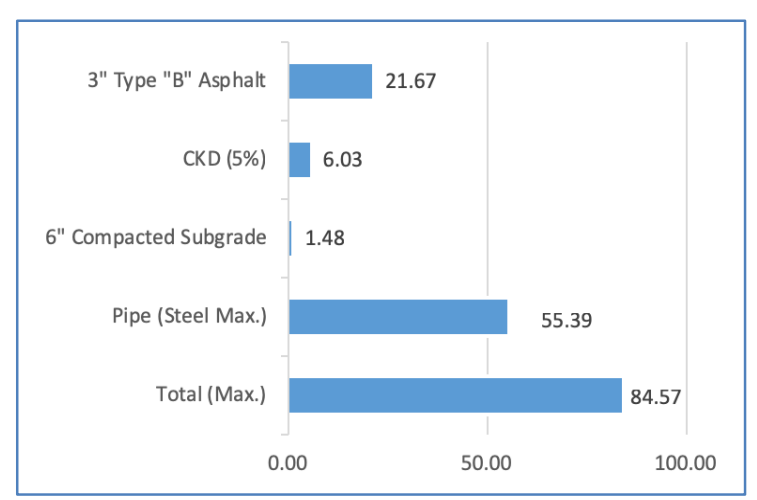

Figure 4. CO2e (kg/lf) using CKD 


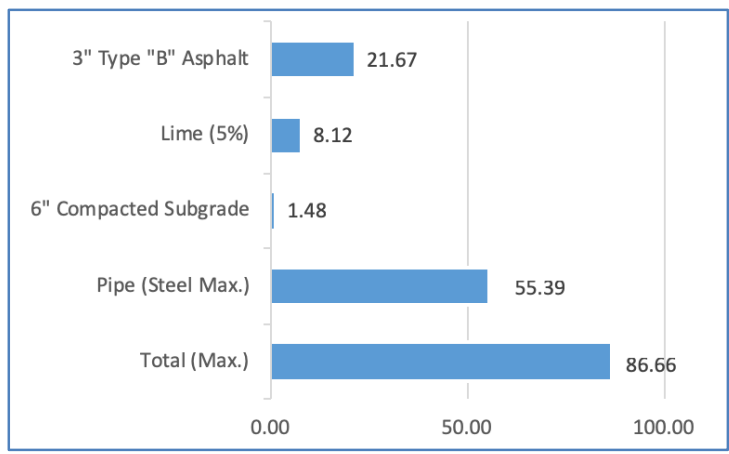

Figure 5. CO2e (kg/lf) using lime

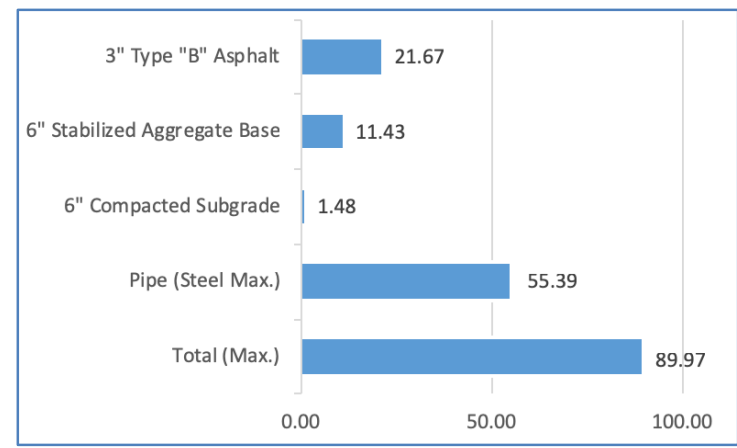

Figure 6. CO2e (kg/lf) using stabilized aggregate base

Maximum CO2e was calculated as $89.97 \mathrm{~kg} / \mathrm{lf}$ by using 3" Type B asphalt, 6" stabilized aggregate base, 6" compacted subgrade and utility steel pipe in OKC. The minimum CO2e emission was calculated as $22.69 \mathrm{~kg} / \mathrm{lf}$ by using 3" Type B asphalt, 6" stabilized aggregate base, fly ash stabilized subgrade, utility HDPE pipe and offset street trees in OKC. Figure 7 and Figure 8 shows the detail of maximum and minimum $\mathrm{CO} 2 \mathrm{e}$ of typical roadway sections of $\mathrm{OKC}$. Maximum worst case $\mathrm{CO} 2 \mathrm{e}$ condition while the minimum $\mathrm{CO} 2 \mathrm{e}$ is relatively

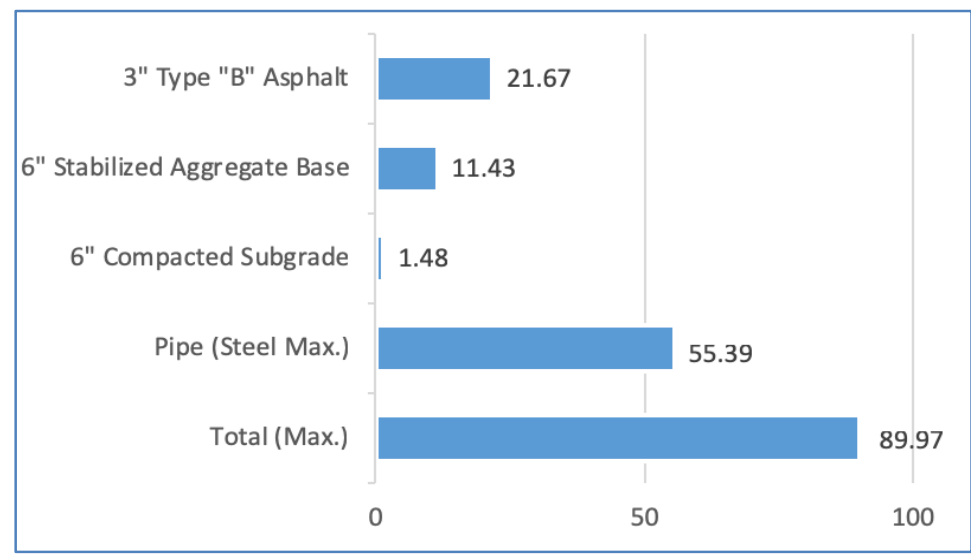

Figure 7. Detail of maximum $\mathrm{CO} 2 \mathrm{e}$ in $\mathrm{OKC}$

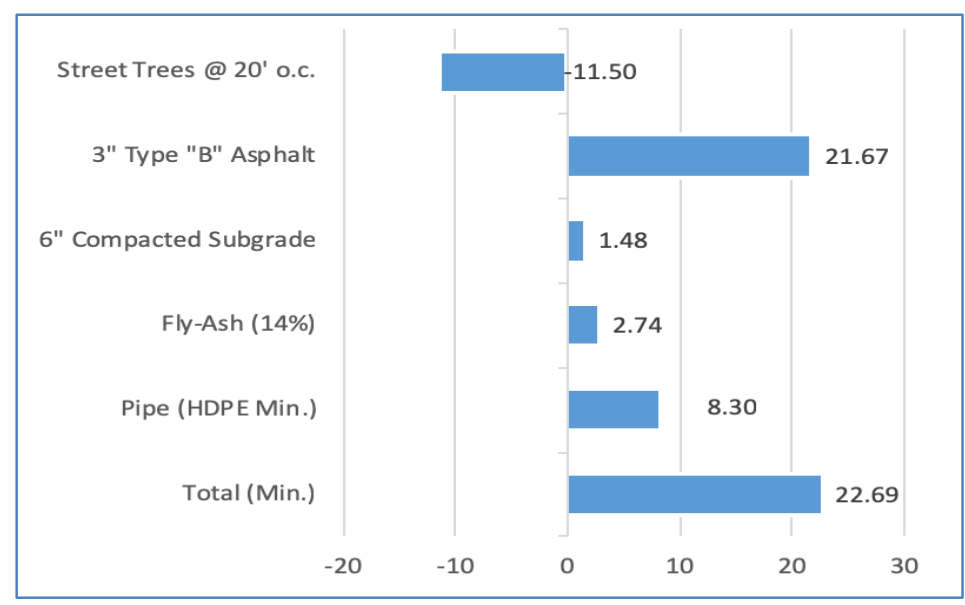

Figure 8. Detail of minimum CO2e of OKC 
In Fishers, the maximum CO2e was calculated as $127.04 \mathrm{~kg} / \mathrm{lf}$ by using 1.5 " Type A HMA surface, 2.5" Type A HMA intermediate, 5.5" Type A HMA base, 6" compacted aggregate base, and utility steel pipe. The minimum CO2e was calculated as $53.26 \mathrm{~kg} / \mathrm{lf}$ by using 1.5" Type A HMA surface, 2.5" Type A HMA intermediate, 2.5" Type A HMA base, 6" compacted aggregate base, fly ash stabilized subgrade, utility HDPE pipe and offset street trees in Fishers. Figure 9 and Figure 10 shows the detail of maximum and minimum $\mathrm{CO} 2 \mathrm{e}$ of typical roadway sections of Fishers. The CO2e for typical roadway sections of Fishers was higher than OKC because Fishers used extra HMA intermediate and base sections.

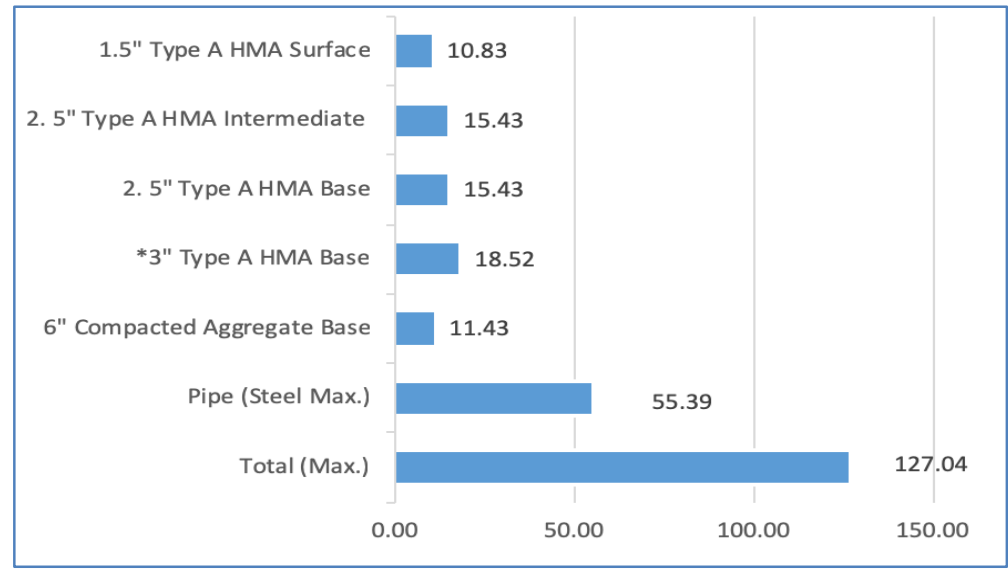

Figure 9. Detail of maximum CO2e of Fishers

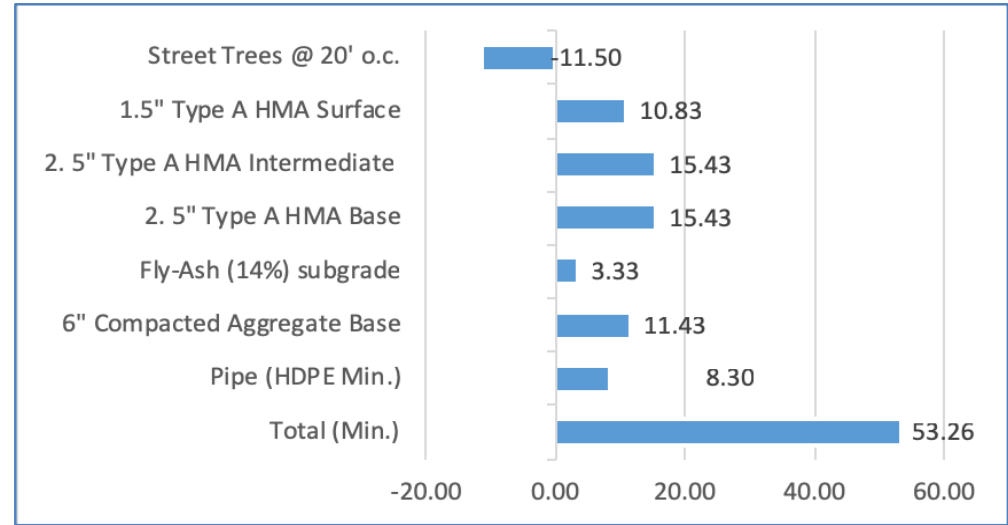

Figure 10. Detail of minimum CO2e of Fishers

\section{CONCLUSION}

Although a large amount of research is now available quantifying the carbon footprint for a variety of construction materials, they do not convert them to match biddable units for U.S. infrastructure construction. However, very little has been published in the area of application of the collected carbon footprint values in U.S. infrastructure construction. This research provides further application of the carbon footprint in infrastructure construction, by applying known carbon footprint values to actual roadway sections in order to calculate a carbon footprint. The carbon footprint per linear foot of roadway construction was determined in GHG/lf, which can be used by owners and designers to make best choices for cost and sustainability.

Reviewing Table 3, using a 12" diameter pipe and weight per linear foot as a basis for consideration, the carbon footprint of typical utility pipe with HDPE produces minimum $\mathrm{CO}_{2} \mathrm{e}$ and steel produces maximum $\mathrm{CO}_{2} \mathrm{e}$. While comparing base materials of fly ash, lime, CKD and aggregates, fly ash stabilized soil base produces minimum $\mathrm{CO}_{2} \mathrm{e}$ and stabilized aggregate base produces maximum $\mathrm{CO}_{2} \mathrm{e}$. While illustrating the comparison of $\mathrm{CO} 2 \mathrm{e}$ of two typical roadway sections of $\mathrm{OKC}$ and Fishers, it is obvious that the two 
municipalities vary in their minimum roadway section and this also causes a dramatic difference in carbon footprint. The maintenance of the two different sections would be at different which would affect the lifecycle carbon footprint which is not considered here. A further look into maintenance would be an obvious next step for research. From the larger perspective, there has been enough information collected and calculated to start producing a carbon footprint for any infrastructure construction project.

\section{REFERENCES}

[1] Santero, N. and Harvath, A. "Global warming potential of pavements," Environmental Research Letters, vol. 4, pp. 034011, 2009.

[2] Collins, F., "2nd generation concrete construction: carbon footprint accounting". Engineering Construction and Architectural Management, vol. 20, no. 4, pp. 330-344, 2013.

[3] Sathaye, N., Horvath, A., and Madanat, S. "Unintended impacts of increased truck loads on pavement supply-chain emissions," Transportation Research Part A, vol. 44, pp. 1-15, 2010.

[4] American Society of Civil Engineers (ASCE), "Report card for America's infrastructure," pp. 153, Washington, DC, Mar 25, 2009, Retrieved from: www.asce.org/reportcard.

[5] Zhang, H., Lepech, M.D., Keoleian, G.A., Qian, S., and Li, C.V. "Dynamic life cycle modeling of pavement overlay systems: Capturing the impacts of users, construction, and roadway deterioration." Journal of Infrastructure Systems, ASCE, vol. 16, no. 4, pp. 299-309, 2010.

[6] Harvey, J.T., J. Meijer, H. Ozer, I.L. Al-Qadi, A. Saboori, and A. Kendall. "Pavement life-cycle assessment framework," Technical Report-FHWA-HIF-16-014; pp. 246, 2016.

[7] Center for Transportation and Planning, "Advancing a sustainable highway system: highlights of FHWA sustainability activities." Washington, DC, 2014, Retrieved from: https://www.sustainablehighways.dot.gov/FHWA_Sustainability_Activities_June2014.aspx

[8] Brown, A. Carbon Footprint of HMA and PCC Pavements. Proceedings International Conference on Perpetual Pavements, Columbus, OH, 2009.

[9] Huang, Y., B. Hakim, and S. Zammataro, "Measuring the carbon footprint of road construction using CHANGER." International Journal of Pavement Engineering, vol. 14, no. 6, 2013.

[10] Cole, R. J. "Energy and greenhouse gas emissions associated with the construction of alternative structural systems," Building and Environment, vol. 34, no. 3, pp. 335-348, 1998.

[11] Barandica, J.M., Fernández-Sánchez, G., Berzosa, A., Delgado, J.A., and Acosta, F.J. "Applying life cycle thinking to reduce greenhouse gas emissions from road projects," Journal of Cleaner Production, vol. 57, pp. 79-91, 2013.

[12] Wang, X., Duan, Z., Wu, L., and Yang, D. "Estimation of carbon dioxide emission in highway construction: a case study in Southwest Region of China," Journal of Cleaner Production, vol. 103, pp. 705-714, 2015.

[13] Melanta, S., Miller-Hooks, E. and Avetisyan, H.G. "Carbon footprint estimation tool for transportation construction projects." Journal of Construction Engineering and Management, vol. 139, no. 5, pp. 547-555, 2012.

[14] Wu, L., Mao, X. and Zeng, A. "Carbon footprint accounting in support of city water supply infrastructure siting decision making: A case study in Ningbo, China," Journal of Cleaner Production, vol. 103 no. 23, pp. 737-746, 2015.

[15] Mao, R., Duan, H., Dong, D., Zuo, J., Song, Q., Gang, L., Hu, M., Zhu, J., and Dong, B. “Quantification of carbon footprint of urban roads via life cycle assessment: Case study of a megacity-Shenzhen, China." Journal of Cleaner Production," vol.166, pp. 40-48, 2017.

[16] Friedrich, E., Pillay, S., \& Buckley, C. "Carbon footprint analysis for increasing water supply and sanitation in South Africa: A case study,” Journal of Cleaner Production, vol. 17, no. 1, pp. 1-12, 2009.

[17] Mosier, R.D., D. Pittenger, and D.D. Gransberg, "Carbon footprint cost index: Measuring the cost of airport pavement sustainability," Transportation Research Board Annual Meeting Compendium of Papers 2014, Paper \#14-3214, 2014.

[18] Liu, X., Q. Cui and C. W. Schwartz, "Introduction of mechanistic-empirical pavement design into pavement carbon footprint analysis," International Journal of Pavement Engineering, pp. 763-771, 2016.

[19] Gopi, V., B. Senior, J. van de Lindt, K. Strong, and R. Valdes Vasquez. "Carbon dioxide equivalency as a sustainability criterion for bridge design alternatives," 53rd ASC Annual International Conference Proceedings, Seattle, WA, 2017.

[20] Chevotis, J. and Galehouse, L. "Energy usage and greenhouse gas emissions of pavement preservation processes for asphalt concrete pavements," First International Conference on Pavement Preservation, pp. 27-42, 2010.

[21] Hammond, G., and C. Jones. "Inventory of carbon and energy (ICE), version 2.0". Circular Ecology, 2011, Retrieved from: http://www.circularecology.com/embodied-energy-and-carbon-footprintdatabase.html\#.WV_wd8bMx-U.

[22] Strohbach, M.W., Arnold, E., and Haase, D. "The carbon footprint of urban green space-a life cycle approach" Landscape and Urban Planning, vol. 104, pp. 220-229, 2012.

[23] Greenroads International., Greenroads Rating System v2. (J.L. Anderson and S.T. Muench, Eds.). Redmond, WA, 2017.

[24] FHWA, "INVEST (Infrastructure Voluntary Evaluation Sustainability Tool) 1.2," Federal Highway Administration, [Online] Available: https://www.sustainablehighways.org, 2015. 
[25] U.S. Green Building Council (USGBC) LEED v.4 for Neighborhood Development, USGBC, 2018, [Online] Available: https://www.usgbc.org/resources/leed-v4-neighborhood-development-current-version.

[26] Institute for Sustainable Infrastructure (ISI), "Envision,” Retrieved from: https://sustainableinfrastructure.org, 2018.

[27] Cement Industry of Canada, "Cement Industry Sustainability Report," 2010.

[28] Asphalt Pavement Alliance, “Carbon Footprint: How Does Asphalt Stack Up?” Asphalt Pavement Alliance, 2010.

[29] Leng, Z., I.L. Al-Qadi, and S. Lahouar. "Development and validation for in situ asphalt mixture density prediction models," NDT \& E International, vol. 44, no. 4, pp. 369-375, 2011.

[30] Asphalt Institute, “Asphalt Pavement Construction FAQs," Asphalt Institute, Retrieved from: http://www.asphaltinstitute.org/asphalt-pavement-construction-faqs/, 2017.

[31] Johnston, D. W. "Formwork for Concrete Chelsea," MI, American Concrete Institute, pp 5-3, 2014.

[32] Collins, R.J., and J.J. Emery, "Kiln Dust-Fly Ash systems for highways bases and sub-bases," Federal Highway Administration, Report No. FHWA/RD-82/167, Washington DC, 1983.

[33] Indiana Department of Transportation (InDOT), "Design Procedures for Soil Modification or Stabilization," Office of Geotechnical Engineering - Production Division, 2008.

[34] American Coal Ash Association (ACAA), "Fly ash facts for highway engineers," Technical Report - FHWA-IF-0319; pp. 74, 2003.

[35] Oklahoma Department of Transportation (OkDOT), Standard Specifications Book, 2009.

[36] Solanki, P., Khoury, N.N. and M.M. Zaman, "Engineering properties of stabilized subgrade soils for implementation of the AASHTO 2002 pavement design guide," Final Report - FHWA-OK-08-10; OkDOT SPR Item Number 2185:131, 2002.

[37] Everett, D. "Organic Act (1890)," The encyclopedia of Oklahoma history and culture, [Online] Available: https://www.okhistory.org/publications/enc/entry.php?entry=OR004. Retrieved Feb. 23, 2019.

[38] American Association of State Highway and Transportation Officials (AASHTO), "A policy on geometric design of highways and streets," 7th Edition. Washington, D.C. American Association of State Highway and Transportation Officials, 2018.

[39] Bouchard, N.R., D.L. Osmond, R.J. Winston, and W.F. Hunt, "The capacity of roadside vegetated filter strips and swales to sequester carbon,” Ecological Engineering; vol. 54, pp. 227-232, 2013.

[40] Nowak, D. J. "Atmospheric carbon dioxide reduction by Chicago's urban forest." In E. G. McPherson, D. J. Nowak, \& R. A. Rowntree (Eds.), Chicago's urban forest ecosystem: Results of the Chicago urban forest climate project. United States Department of Agriculture, Forest Service, pp. 83-94, 1994.

[41] Akbari, H. "Shade trees reduce building energy use and $\mathrm{CO} 2$ emissions from power plants," Environmental Pollution, vol. 116, pp. S119-S126, 2002.

[42] McPherson, E.G., and Simpson, J.R. "Carbon dioxide reductions through urban forestry: guidelines for professional and volunteer tree planters," Gen. Tech. Rep. PSW-171. Albany, CA, USDA Forest Service, Pacific Southwest Research Station, 1999.

[43] Townsend-Small, A. \& Czimczik, C. I. Correction to "Carbon sequestration and greenhouse gas emissions in urban turf," Geophysical Research Letters, vol. 37, no. 6, 2010.

[44] McHale, M.R., Hall, S.J., Majumdar, A. and Grimm N.B. "Carbon lost and carbon gained: a study of vegetation and carbon trade-offs among diverse land uses in Phoenix, Arizona," Ecological Applications, vol. 27, no. 2, pp. 644-661, 2017.

[45] Collins, F. "Inclusion of carbonation during the life cycle of built and recycled concrete: influence on their carbon footprint," The International Journal of Life Cycle Assessment, vol. 15, no. 6, pp. 549-556, 2010.

[46] Mukherjee, A., B. Stawowy, and D. Cass, "Project emissions estimator (PE-2): Tool to Aid contractors and agencies in assessing greenhouse gas emissions of highway construction projects," Transportation Research Record 2366. Transportation Research Board, Washington, DC, 2013.

[47] Melson, S.L., M.E. Harmon, J.S. Fried, and J.B. Domingo, "Estimates of live-tree carbon stores in the Pacific Northwest are sensitive to model selection,"Carbon Balance and Management, vol. 6, no. 2, 2011.

[48] Tang, Y., A. Chen, and S. Zhao, "Carbon storage and sequestration of urban street trees in Beijing, China," Frontiers in Ecology and Evolution; vol. 4, no. 53, May 2016.

[49] Mosier, R.D., Mohanty, S.K., and Adhikari, S. "Carbon footprint calculation for a typical roadway section" Conference Proceedings, Associated Schools of Construction April 2018.

\section{BIOGRAPHIES OF AUTHORS}

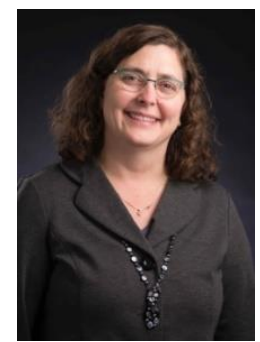

With experience as a structural engineer and municipal project manager, Mosier has experience in both commercial and heavy construction. This combination has focused her research on sustainability in buildings and roadways. Mosier has been at Oklahoma State University for five years and has fifteen years of construction experience. 


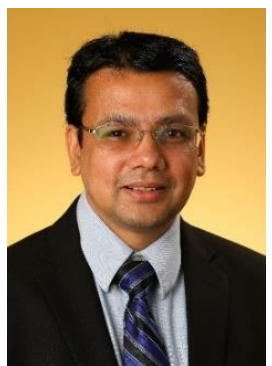

Dr. Sanjeev Adhikari is faculty from Kennesaw State University. Previously he was faculty at Morehead State University from 2009 to 2016 and faculty at Purdue University - Indianapolis from 2016 to 2019. He has completed Ph.D. degree in civil engineering, focusing on construction management from Michigan Technological University in 2008. He has an extensive teaching background with a total of 18 years of the academic experience at five different universities. To supplement his teaching and research, he has been involved in numerous professional societies, including ASCE, ACI, ASEE, ASC, ATMAE, and TRB. His research output has been well disseminated as he has published thirty journal papers and thirty-nine conference papers. His research interests are 1) Construction Sustainable and Resilient, 2) Structural BIM Integration, 3) Carbon Footprint Analysis on Roadways.

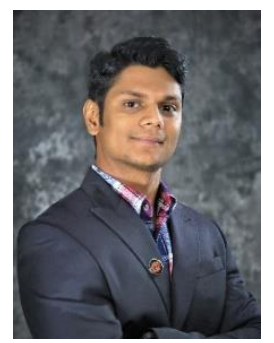

Saurav Kumar Mohanty has worked as a Graduate Research Assistant while seeking his Master's Degree in Civil Engineering at Oklahoma State University. Saurav has excellent construction experience and has a zest for research. He has worked in the Construction Industry in India for approximately one and a half years as a Construction Project Engineer \& is presently working as Project Controls Egineer at SoCalGas in Los Angeles.

Further Saurav performed research as part of his undergraduate degree in Manipal Institute of Technology, which resulted in a publication. During his master's degree, he has also published an additional paper, Carbon Footprint Calculation for a Typical Roadway Section." 